\title{
Effect of diet on amino-acid profile of duodenal digesta in the goat
}

\author{
H Archimède 1, D Sauvant ${ }^{1}$, M Dorléans ${ }^{1}$, JC Robert ${ }^{2}$ \\ 1 INRA, station de nutrition et alimentation de IIINA-PG, 16, rue Claude-Bernard, 75005 Paris; \\ 2 Rhóne Poulenc Nutrition Animale, 03600 Commentry, France
}

Amino-acid profiles (AAP) of duodenal digesta were measured in an experimental design combining 2 roughages (maize stover, MS, and alfafa hay, $\mathrm{AH}$ ), 3 concentrates FS ( $24 \%$ wheat; $24 \%$ barley; $24 \%$ oats; $10 \%$ soybean meal; $10 \%$ pea), SS $(52 \%$ maize; $20 \%$ sorghum; $10 \%$ coconut meal; $10 \%$ soybean meal), DF ( $39 \%$ soybean hulls; $19 \%$ gluten feed; $14 \%$ beet pulp; $10 \%$ coconut meal; $10 \%$ soybean meal) and 3 levels of incorporation $(0,30,60 \%)$. A total of 58 microbial nitrogen analyses (purine method) were performed on non-lactating goats at maintenance (4-5 repetitions for each diet). Fourteen duodenal AAP were assayed pooling samples by diets. Statistical analysis of AAP was performed to test the effects of the nature of roughage and concentrate, and the level of concentrate.

The duodenal AAP varied widely between rations (table I). Diet (roughage, concentrate nature and level) explained $0 \%$ (Arg), $24 \%$ (Lys)
$26 \%$ (Cys), $50 \%$ (lle), 61\% (His) $61 \%$ (Val), $61 \%$ (Leu), $74 \%$ (Phe), $77 \%$ (Met), and $90 \%$ (Val) of the variations in the relative proportions of the amino acids in the duodenal digesta. Nevertheless, concentrate levels had no influence on the essential amino acids except for $\mathrm{Val}$ and Thr. Compared with MS, AH significantly decreased the concentration of Met + Cys whereas an opposite tendency was observed for His, lle and Phe.

Concentrations of Thr, Val, lle, Phe, Asp, Gly decreased whereas Asp and Gly increased with increasing proportions of microbial nitrogen in the total duodenal nitrogen. This last ratio was higher with MS than $\mathrm{AH}$.

The duodenal/ingested nitrogen ratio explained a variable part of AAP: Pro(29\%); His(31\%); $\operatorname{Thr}(37 \%)$; Ser $(39 \%)$ and Met + Cys $(54 \%)$. The proportions of His and Pro were negatively related with this ratio whereas an opposite tendency appeared with the other amino acids.

Table I. Mean AAP of the duodenal digesta according to the diet.

\begin{tabular}{|c|c|c|c|c|c|c|c|c|c|c|c|c|}
\hline Diet effect & Lys & Met + Cys & Arg & His & $\| \theta$ & Leu & Phe & Thr & Val & $N E A A$ & $N m$ & $N d$ \\
\hline MS & 6.4 & $3.4^{\mathrm{a}}$ & 4.9 & 2.0 & $5.5 \mathrm{a}$ & 8.9 & $5.1^{\mathrm{a}}$ & 5.7 & 6.5 & 52 & 39 & $124^{a}$ \\
\hline $\mathrm{AH}$ & 6.5 & $3.0^{\circ}$ & 4.4 & 2.3 & $5.7^{b}$ & 9.0 & $5.4^{b}$ & 5.6 & 6.5 & 52 & $34^{b}$ & $75^{b}$ \\
\hline FS & $6.1^{a}$ & 3.0 & 4.8 & 2.2 & $5.4 \mathrm{a}$ & $9.5^{a}$ & 5.3 & $5.4 \mathrm{a}$ & $6.3^{a}$ & $52^{b}$ & 39 & 84 \\
\hline SS & $6.9^{\mathrm{b}}$ & 3.2 & 4.7 & 2.0 & $5.7 \mathrm{ab}$ & 8.4 & 5.3 & $5.8^{b}$ & 6.5 & 51 ab & 37 & 94 \\
\hline DF & $6.0^{a}$ & $3 . \overline{3}$ & 4.2 & 2.1 & $5.6^{a}$ & 8.9 & 5.1 & $5.6 \mathrm{ab}$ & 6.7 & $53^{a}$ & 37 & 97 \\
\hline $0 \%$ & 6.9 & 3.4 & 5.0 & 2.2 & 5.6 & 8.6 & 5.5 & 6.0 & $6.6 \mathrm{ab}$ & $50 \mathrm{a}$ & 32 a & 146 \\
\hline $30 \%$ & 6.3 & 3.2 & 4.2 & 2.1 & 5.7 & 9.0 & 5.3 & 5.7 & $6.6 \mathrm{a}$ & 52 & $37 a b$ & $99 a b$ \\
\hline $60 \%$ & 6.4 & 3.2 & 4.9 & 2.2 & 5.5 & 9.0 & 5.2 & $5.4^{\mathrm{a}}$ & $6.4^{b}$ & 52 & $38 \mathrm{~b}$ & $85^{b}$ \\
\hline
\end{tabular}

Amino acid expressed as $\mathrm{g}$ per $100 \mathrm{~g}$ total amino acid; $\mathrm{Nm}=$ microbial nitrogen as $\mathrm{g}$ per $100 \mathrm{~g}$ duodenal nitrogen; $\mathrm{Nd}=$ duodenal nitrogen as $\mathrm{g}$ per $100 \mathrm{~g}$ ingested nitrogen; $\mathrm{NEAA}=$ non-essential amino acid; $\mathrm{MC}=$ methionine + cysteine. 